\title{
A EXEGESE DE D. 33,2,15,1 (MARCELO, L. XIII DIG.) EM TEMA DE CONSTITUIÇÃO TÁCITA DE SERVIDÃO PREDIAL POR "DESTINAÇÃO dO PROPRIETÁRIO"
}

\author{
Eduardo César Silveira Vita Marchi \\ Professor Associado do Departamento de Direito Civil da Faculdade de Direito da USP \\ Livre-docente em Direito Romano do Departamento de Direito Civil \\ da Faculdade de Direito da USP \\ Doutor em Direito Romano pela Universidade de Roma
}

\begin{abstract}
Resumo:
Em tema de constituição tácita de servidão predial por "destinação do proprietário" preponderam ainda na doutrina romanística os resultados obtidos por Riccobono, que sustentou, com base na demonstração de uma série de interpolações, tratar-se tal instituto de uma inovação do direito justinianeu.

Mediante a revisão e releitura dos passos do Digesto concernentes à matéria, e, em particular, com a prova da substancial genuinidade do fragmento clavis huius materiae (D. 33,2,15,1), procura o autor propugnar a refutação definitiva da tese riccoboniana, mostrando que o direito romano, em toda a sua evolução, não teria jamais admitido a constituição tácita de servidão predial.
\end{abstract}

\section{Abstract:}

Regarding the implied creation of praedial servitudes by "act of the owner", the prevailing Roman law doctrine is that of Riccobono, stating (with support of the evidence of a series of interpolations) that such an institute is an improvement of Justinian's law.

Thanks to the revision and rereading of the Digest's texts concerning the matter and particularly through the evidence demonstrating the authenticity of D. 33,2,15,1 (clavis huius materiae), the author tries to refute Riccobono's doctrine showing that throughout it's long evolution Roman law never knew the notion of the implied establishment of praedial servitudes.

\section{INTRODUÇÃO}

Uma das vexatae questiones da moderna ciência romanística diz respeito ao problema da eficácia, em direito romano, da chamada "destinação do paterfamilias" (proprietário), ou, em outros termos, da constituição tácita de servidões prediais, instituto não contemplado expressamente pelo nosso Código 
Civil, não obstante a sua admissibilidade, segundo parte da doutrina brasileira, com base na sistemática do nosso ordenamento.

Ao fim do século passado, durante o apagar-se dos estudos pandectísticos, vinha à luz um fundamental estudo de Riccobono, ${ }^{1}$ no qual o autor, relevando uma série de interpolações em alguns passos do Digesto, em especial D. 33,2,15,1, sustentava a tese, pela primeira vez, de que a destinação do paterfamilias tivesse sido uma inovação do direito justinianeu. Tal resultado, malgrado a distância do tempo e as várias retificações ulteriores, é ainda hoje acolhido em grande parte pela romanística.

Mediante a revisão dos passos do Digesto concernentes à matéria, e, em particular, com a prova da substancial genuinidade do fragmento clavis huius materiae - D. 33,2,15,1 procuramos demonstrar com nossas pesquisas em tema de destinação do paterfamilias (das quais a presente comunicação é uma das partes) que deve ser definitivamente refutada a tese riccoboniana: o direito romano, em toda a sua evolução, não teria jamais admitido uma constituição tácita de servidão predial.

\section{NOÇÃO DO INSTITUTO CHAMADO "DESTINAÇÃO DO 'PATERFAMILIAS"}

A chamada "destinação do paterfamilias", ou, mais exatamente, a "destinação do proprietário", vem comumente identificada, na moderna terminologia, com aquele especial modo de constituição de servidões prediais que se opera tacitamente, em base a um preexistente estado de serviço observado entre dois imóveis - ou entre duas partes de um imóvel de um mesmo proprietário anterior.

Em outros termos: quando entre dois ou mais imóveis, ou entre partes de um imóvel - pertencentes a um único proprietário, se estabelece uma permanente relação de subordinação, pela qual um deles é destinado ao serviço do outro (limitando, portanto, o direito de gozo de um em favor da utilidade do outro), não existe servidão, em face do princípio, sempre vigente, "nemini res sua servit", ou seja, não pode constituir-se uma servidão entre dois imóveis de um

1. La destinazione del padre di famiglia, Rivista italiana per le scienze giuridiche, n. 21, p. 380$421,1896$. 
mesmo proprietário; ${ }^{2}$ se, porém, por efeito de um ato inter vivos ou por disposição mortis causa venham a pertencer a proprietários diversos, aquele precedente estado de serviço transforma-se automaticamente em servidão predial, a partir do momento da simples separação dos imóveis.

Não existindo, portanto, qualquer disposição relativa à servidão predial, esta vem tacitamente constituída, ou seja, sem qualquer título específico, com base na vontade presumida das partes (ausente disposição em contrário) ou do disponente, deduzida da destinação do proprietário, isto é, daquela "servidão de fato" - ou actum servitutis, como se expressava o máximo expoente da Escola dos Comentadores, Bártolo de Saxoferrato, ${ }^{3}$ considerado por muitos o verdadeiro criador do nosso instituto predisposta pelo único proprietário anterior.

III. A EXEGESE DE D. $33,2,15,1$

III.1. A "fattispecie"

Passemos à análise do texto mais complexo em matéria de constituição tácita por destinação do paterfamilias, justamente considerado por Riccobono como clavis huius materiae:

D. 33,2,15,1 (Marcellus, 1.XIII digestorum): "Qui duos fundos habebat, unum legavit et alterius fundi usum fructum alii legavit: quaero, si fructuarius ad fundum aliunde viam non habeat quam per illum fundum qui legatus est, an fructuario servitus debeatur. Respondit, quemadmodum, si in hereditate esset fundus, per quem fructuario potest praestare via, secundum voluntatem defuncti videtur id exigere ab herede, ita et in hac specie non aliter concedendum esse legatario fundum vindicare, nisi prius ius transeundi usufructuario praestet, ut

2. Cf. D. $8,2,26$ (Paulus, 1. XV ad Sab.) = art. 1.027 do C.C. italiano $=$ art. 695 do C.C. brasileiro.

3. Bartolus a Saxoferrato in secundam infortiati partem, Venetiis, 1575, ad legem "qui duas tabernas", p. 69. 
haec forma in agris servetur, quae vivo testatore optinuerit, sive donec usus fructus permanet sive dum ad suam proprietatem redierit".

D. 33,2,15,1 (Marcelo, 1. XIII dig.): "Aquele que tinha dois imóveis legou um deles, e a outro legatário legou o usufruto do outro imóvel. Não possuindo o usufrutuário outra via de acesso ao imóvel do que através daquele imóvel que fora legado, pergunto se é devida uma servidão ao usufrutuário. Respondeu que, como fizesse parte da herança aquele imóvel pelo qual podia-se prestar o acesso ao usufrutuário, parecia possível exigir isto do herdeiro; assim também, neste caso, não se deveria conceder a reivindicatória ao legatário, a não ser que este outorgasse o direito de acesso ao usufrutuário, de modo que se conservasse naqueles campos o estado de coisas que teria prevalecido vivendo o testador, ou até quando durasse o usufruto ou até que se consolidasse a nua-propriedade".

No seu testamento, o proprietário de dois imóveis lega a propriedade de um deles a uma determinada pessoa e, a uma outra, lega o usufruto do imóvel restante. Apresentam-se, portanto, três situações jurídicas: a. aquela do legatário de um dos imóveis que dele é, portanto, proprietário; b. aquela do herdeiro, nu-proprietário do outro imóvel; c. aquela do legatário do usufruto do imóvel destinado ao herdeiro. Não possuindo o usufrutuário acesso ao imóvel a não ser através do outro imóvel, indaga-se se lhe é devida a servidão (obviamente de passagem). A pergunta causa surpresa já que admite a possibilidade de que uma servidão seja devida a quem não é proprietário, ou seja, ao usufrutuário.

O jurista responde que, fazendo parte da herança o imóvel encravante, pode-se exigir do herdeiro o acesso para o usufrutuário segundo a vontade do defunto, e que se deve conceder ao legatário a possibilidade de reivindicar o imóvel encravante com a condição que este preste, primeiramente, o ius transeundi ao usufrutuário. Tal, se decidia, declara o fecho do passo, a fim de que se conservasse nos campos o estado de coisas que teria prevalecido 
vivendo o testador, enquanto durasse o usufruto ou até que a propriedade do herdeiro retornasse com toda a sua eficácia.

III.2. Propostas de reconstrução

Baseando-se principalmente neste texto, Riccobono ${ }^{4}$ defende a tese, fundamental em tema de destinação do paterfamilias, segundo a qual o direito justinianeu teria introduzido o princípio pelo qual o estado de serviço anterior entre dois imóveis de um mesmo proprietário devesse permanecer ainda posteriormente à transferência dos mesmos a proprietários diversos, sob a forma de verdadeira servidão, sendo que tal solução deveria ser reconduzida, segundo os compiladores, à vontade do antigo proprietário.

Do passo em exame deduzir-se-ia, antes de tudo, observa Riccobono, a obrigação do herdeiro de prestar a passagem ao legatário do usufruto de um imóvel sem acesso, já que se tratava de um daqueles adminicula ususfructus $;{ }^{5}$ de outro lado, não sendo proprietário, o usufrutuário estaria impedido juridicamente de constituir em seu favor a servidão de passagem. A importância, porém, do texto em matéria de destinação do paterfamilias residiria, segundo Riccobono, na expressão "secundum voluntatem defuncti" e no fecho "ut haec forma...redierit".

Na primeira frase identifica Riccobono uma alusão à vontade presumida do disponente, em base à qual declarar-se-ia no fecho do passo que os imóveis deveriam "conservare presso $i$ successori quella stessa disposizione $e$ forma che ebbero dal testatore, e ciò non solo per quel tempo che dura o usufrutto, ma anche dopo che lo stesso si è consolidato alla proprietà" ${ }^{6}$ Esta última solução não poderia ser clássica. Marcelo admitiria apenas a obrigação do herdeiro de prestar o acesso ao usufrutuário, o qual não poderia sozinho providenciar a constituição da servidão. Não teria jamais dito que o estado de serviço anterior entre dois imóveis devesse permanecer ainda posteriormente à extinção do usufruto. Baseando-se em D. 7,6,1,1-4, o herdeiro seria obrigado unicamente a
4. Ob. cit., p. 397 ss.
5. Cf. D. 7,6,1,1-4, D. 8,5,2,2 e Frag. Vat. 54 .
6. Ob. cit., p. 398. 
prestar o acesso ao usufrutuário, ou seja, apenas os meios estritamente necessários (D. 7,6,1,3) à fruição da coisa legada. Em conseqüência, Riccobono releva a interpolação da expressão "secundum voluntatem defuncti" e do fecho "ut haec forma...redierit", já que pela primeira vez viria reconhecido o princípio pelo qual aquele estado de serviço anterior predisposto pelo testador devesse permanecer, com base na sua vontade presumida, posteriormente à divisão dos imóveis.

A tese de Riccobono foi acolhida pela maioria dos autores que se ocuparam do tema, principalmente no que se refere à interpolação do fecho "ut haec forma ... redierit". 7

O passo vem, pois, reconstruído pela communis opinio da seguinte maneira:

"Qui duos...legavit: quaero...an fructuario [servitus] ('via' ou 'praestari via') debeatur. Respondit...[ut haec

7. Julgam interpolado o fecho "ut haec forma...redierit": Ferrini, contranota " $\mathrm{v}$ " in Gluck \& Salkowski, Ausführliche Erläuterung der Pandecten nach Hellfeld ein Commentar, Erlangen, 1889 (trad. ital. de Ferrini, Commentario alle Pandette, série dos livros XXX-XXXII, segunda parte, Milano, Società Editrice Libraria, 1901, p. 78); Manuale di Pandette, $2^{\mathrm{a}}$ ed., Milano, Società Editrice Libraria, 1900, p. 496, n.2; Bonfante, Istituzioni di diritto romano, $8^{\mathrm{a}}$ ed., Milano, Vallardi, 1925, p. 345; Corso di diritto romano III - Diritti reali, Roma, 1933 (reedição da $1^{\text {a }}$ ed. organizada por Giuliano Bonfante e Giuliano Crifò, Milano, Giuffrè, 1972), p. 147; Grosso, In tema di costituzione tacita di servitù, $B I D R$, n. 42, p. 327-328, 1934; Le servitù prediali nel diritto romano, Torino, Giappichelli, 1969, p. 223; Usufrutto e figure affini nel diritto romano, $2^{2}$ ed., Torino, Giappichelli, 1958, p. 199; Frezza, Appunti esegetici in tema di modi pretorii di costituzione dell'usufrutto e delle servitù prediali, Rivista dell' Università di Cagliari, n. 30, p. 21, 1933-1934; Biondi (com exceçāo das palavras "donec usus fructus permanet"), La categoria romana delle "servitutes", Milano, Società Editrice Vita e Pensiero, 1938, p. 225-227; Le servitù prediali nel diritto romano - Corso di lezioni, $2^{\text {a }}$ ed., Milano, Giuffrè, 1954, p.. 289-291; Ciapessoni (com exceção das palavras "donec usus fructus permanet"), "Servitus personae" e "usus personae", in Per il XIV centenario della codificazione di Giustiniano, Pavia, 1934, p. 920 ss.; Solazzi (modificado já a partir de "nisi prius"), Requisiti e modi di costituzione delle servitù prediali, Napoli, Jovene, 1947, p. 186 ss.; "Servitutem debere", IURA, n. 2, p. 13, 1951; Bonet, Correa \& Calderón (com exceção das palavras finais "sive donec...redierit"), Sobre la supuesta costitución tácita de las servidumbres en las fuentes jurídicas romanas, $A H D E$, n. 19, p. 326-328, 1948-49; Crifò (com exceção das palavras finais "sive donec...redierit"), Destinazione del padre di famiglia (Diritto Romano e intermedio) in Enciclopedia del diritto, Milano, Giuffrè, 1963, v. XII, p. 309-310 e n. 13; e Reggi, Note anonime ai "digesta" di Marcello, Studi Parmensi, n. 4, p. 60-61, 1954. 


\begin{abstract}
forma in agris servetur quae vivo testatore optinuerit sive] donec (='dum') usus fructus permanet [sive dum ad suam proprietatem redierit]".
\end{abstract}

Diverso é o nosso parecer. Ao contrário de Riccobono, entendemos ser o passo de Marcelo substancialmente genuíno; de outro lado, julgamos inexistente no mesmo texto qualquer reconhecimento por parte do direito justinianeu de uma constituição tácita por destinação do paterfamilias.

Não nos parece exata a leitura da parte final do passo na forma proposta por Riccobono, já que existem graves problemas que não são enfrentados e convincentemente resolvidos. Seria preciso, antes de mais nada, determinar qual seria a natureza daquele acesso devido pelo herdeiro em favor do usufrutuário. Seria simplesmente, como resulta da explanação de Riccobono, um ius transeundi (passagem temporânea) devido ao usufrutuário como um acessório do seu direito de usufruto (já que ele, não sendo proprietário, não poderia adquirir uma servidão)? Salkowski, ${ }^{8}$ tratando deste primeiro problema, faz uma observação importantíssima para esclarecer a questão: se é verdade que o usufrutuário não poderia exigir do legatário do imóvel encravante a constituição de uma servidão predial, não se deveria deduzir, como parece fazer Riccobono, que a única solução seja a prestação de uma passagem com base em um direito pessoal de conteúdo similar à servidão. Poderia o herdeiro, dizia o autor, "già costringere mediante eccezione di dolo il legatario, che si fa avanti colla sua domanda, a costituire una regolare servitù per l'altro fondo" ${ }^{9}$ Contra tal solução poder-se-ia objetar que, em relação ao usufrutuário, importaria unicamente que lhe fosse concedido o simples acesso, seja este representado por uma servidão predial ou mesmo por um direito pessoal de igual conteúdo. Adverte, porém, Salkowski que esta questão não seria de escassa importância: surgiriam graves dificuldades, diz o autor, se o usufrutuário, por exemplo, cedesse o exercício do usufruto a uma outra pessoa. Tratando-se unicamente de um direito pessoal, o cessionário não teria a possibilidade de exigir do herdeiro a
8. Ob. cit., p. 80 ss.
9. Ob. cit., p. 83. 
concessão da passagem e nem mesmo poderia, não sendo proprietário, providenciar a constituição da servidão.

Da tese de Riccobono deduz-se que a solução clássica não se referiria jamais a uma verdadeira servidão de passagem; assim o herdeiro na reivindicatio teria excetuado somente um ius transeundi de caráter pessoal, temporaneamente devido ao usufrutuário. Este resultado, em nossa opinião, deve ser refutado: excetuando o herdeiro, na reivindicatio, simplesmente um ius transeundi de caráter pessoal em favor do usufrutuário, dever-se-ia concluir que, extinto o usufruto, o herdeiro não teria nenhum meio para conseguir o acesso no caso em que o legatário negasse tal concessão, mesmo prontificando-se o herdeiro a adquiri-lo.

Parece-nos, portanto, completamente inverossímil que a jurisprudência clássica, defronte a todas estas conseqüências, não pensasse em proteger o herdeiro em uma tal situação. Entendemos, pois, que a solução presente no fecho do passo seja substancialmente genuína: concede-se a oportunidade ao herdeiro na reivindicatio de exigir do legatário do imóvel encravante, através da exceptio doli, a constituição não simplesmente de um ius pessoal de trânsito em favor do usufrutuário, mas, ao contrário, de uma verdadeira servidão de passagem em seu favor na qualidade de nu-proprietário do imóvel encravado. Pode-se, portanto, fixar, em resumo, os pontos principais do nosso raciocínio: 1. a necessidade da passagem; 2. a concessão de meios seguros para obter o acesso; 3 . as dificuldades derivantes da prestação de um simples direito pessoal de passagem.

Com uma tal solução, Marcelo, ao mesmo tempo, atenderia aos interesses do usufrutuário e do herdeiro nu-proprietário, fruindo o primeiro da servidão de passagem constituída em favor do segundo.

Análogos resultados na exegese de D. 33,2,15,1 obtém Astolfi que, único entre os modernos autores que se ocuparam do texto em matéria de destinação do paterfamilias, sustenta, ao contrário da tese riccoboniana, a substancial genuinidade do fecho "ut haec forma ... redierit".

Deve-se, porém, refutar, dentro de certos limites, o motivo principal alegado por Astolfi segundo o qual dever-se-ia considerar genuína no texto a constituição de uma verdadeira servidão, ou seja, o fato de que seja admitido o herdeiro, e não o usufrutuário, na oposição da exceptio doli a fím de 
se obter a passagem. Não nos parece que esta legitimidade, como sustenta Astolfi, possa ser citada como prova da classicidade do passo em exame. Do exame em conjunto da "fattispecie" resulta, além da necessidade futura para o herdeiro daquela servidão necessária, também a necessidade imediata do usufrutuário de obter o aditus. Em uma tal situação a prestação do acesso é exatamente, como declaram as fontes $\quad$ D. 30,44,9 e D. 7,6,1,1-4 - ônus do herdeiro. Em D. 33,2,15,1, como dissemos, concede-se a possibilidade ao herdeiro de opor a exceptio doli contra o legatário do imóvel encravante a fim de que este preste o acesso ao usufrutuário; é lícito, porém, pensar-se que, caso o herdeiro não procedesse de tal maneira, o usufrutuário teria à sua disposição uma vindicatio ususfructus contra aquele a fim de obter a passagem. Assim, a legitimidade do herdeiro para a exceptio doli é perfeitamente lógica, ainda que se admitisse, contrariamente às nossas idéias e àquelas de Astolfi, que a solução clássica se referisse unicamente à passagem temporânea em favor do usufrutuário. Tal raciocínio não pode, portanto, constituir-se em um elemento probatório da tese segundo a qual a decisão genuína contemplaria uma verdadeira constituição de servidão.

De outro lado, do exame de D. 33,2,15,1 observa-se que, ao contrário do que afirma Astolfi, nem mesmo no direito justinianeu viria reconhecida uma verdadeira constituição tácita de servidão. Oposta pelo herdeiro a exceptio doli, o legatário teria êxito na reivindicatio somente se prestasse o ius transeundi, ou, em outros termos, se constituísse a servidão de passagem. A constituição da servidão, deste modo, não se dá jamais tacitamente, uma vez que o legatário tem unicamente a obrigação de constitui-la a fim de obter êxito na reivindicatio.

O passo, portanto, é substancialmente genuíno, mesmo tratando-se de um resumo compilatório.

\section{CONCLUSÕES}

Entendemos, portanto, que já a jurisprudência clássica, nos casos em que de uma herança resultasse um imóvel encravado, julgasse, com base na vontade presumida do de cuius, que haveria uma obrigação do destinatário do 
imóvel encravante de constituir uma servidâo de passagem em favor do imóvel encravado destinado ao herdeiro ou legado a uma terceira pessoa.

Para render eficaz tal vontade, a jurisprudência, de acordo com cada caso, concederia a exceptio doli ou uma actio ex testamento. Poder-se-ia pensar no caso em que, ao contrário do que se verifica no texto de Marcelo, o imóvel encravado não fosse destinado ao herdeiro, mas a um legatário, restando ao herdeiro o imóvel encravante. A jurisprudência coloca à disposição, no caso de legado per damnationem do imóvel encravado, uma actio ex testamento ao legatário, a fim de que este exija do herdeiro a constituição da servidão necessária; nesta mesma hipótese, tratando-se de legado per vindicationem é provável que se concedesse, com a mesma finalidade, uma exceptio doli ao legatário contra a actio negatoria proposta pelo herdeiro para impedir-lhe a passagem.

O herdeiro, de outro lado, que recebesse o imóvel encravado teria contra o legatário do imóvel encravante, independentemente do tipo legado, uma exceptio doli com a qual poderia paralisar a ação daquele último (actio ex testamento ou reivindicatio), enquanto o mesmo legatário não constituísse a servidão necessária.

$\mathrm{Na}$ hipótese, ao contrário, de legado dos dois imóveis, encravante e encravado, parece-nos que se concederia igualmente a exceptio doli ao legatário do imóvel encravado contra a actio negatoria do legatário do imóvel encravante, ação esta destinada a vetar a passagem.

O mesmo raciocínio, aplicado nos casos em que se apresentasse um legado per damnationem, seria exigido mutatis mutandis nas hipóteses de fideicomisso.

Tais soluções, além de se basearem nos testemunhos de $D$. $33,2,15,1$, D. $30,81,3$, D, $8,5,20$ pr. e D. $33,3,1$, encontrariam confirmação, ainda que indireta, em um texto de Florentino (D. 30,116,4 - 1. XI inst.: "Fundus legatus talis dari debet, qualis relictus est. Itaque sive ipse fundo heredis servitutem debuit sive ei fundus heredis, licet confusione dominii servitus extincta sit, pristinum ius restituendum est. Et nisi legatarius imponi servitutem patiatur, petendi ei legatum exceptio doli mali opponetur: si vero fundo legato servitus non restituetur, actio ex testamento superest"), que concede, para a nova constituição das servidões extintas por confusão por efeito de disposição testamentária, os remédios da 
actio ex testamento e da exceptio doli. Deve-se dizer, porém, que nos escassos textos que se referem diretamente ao nosso problema, o único caso contemplado é aquele no qual o imóvel encravado é destinado ao herdeiro, sendo legado per vindicationem ou per damnationem, ou cedido por fideicomisso, o imóvel encravante: nestas hipóteses, concede-se expressamente ao herdeiro, a fim de obter a constituição da servidão necessária, a exceptio doli contra a reivindicatio do legatário (D. $33,2,15,1$ ou D. $8,5,20$ pr.) ou mesmo contra a petitio fideicommissi (D. 8,5,20 pr.) proposta pelo fideicomissário do imóvel encravante.

A obrigação de constituição da servidão necessária resulta claramente tanto dos textos que se referem diretamente ao nosso tema, como, por exemplo, D. 30,81,3 e D. 8,5,20 pr., quanto indiretamente de outros passos como D. 8,2,10 (no qual deve-se observar a forma na qual vem formulada a segunda pergunta "et de illo...debet").

Através destes mecanismos, a jurisprudência clássica, mesmo sendo praticamente revogado, em certo sentido, o rígido princípio da constituição nominatim, conseguia, de maneira arguta, evitar ferir mortalmente tal regra: formalmente a servidão continuava a ser constituída expressamente (nominatim), como exigido pelo ius civile, se bem que a imposição da obrigação de constituir a servidão necessária derivasse tacitamente da vontade do testador. 